\title{
EFFECT OF THERMOMECHANICAL PROCESSING
}

\author{
ON THE PROPERTIES OF INCONEL ${ }^{\circledR} 706$ ALLOY
}

\author{
A.I. Kahveci, A.K. Chakrabarti, K.P. Kinnear, G.W. Kuhlman, R.A. Beaumont \\ Alcoa Laboratories and Alcoa Forged Products
}

\begin{abstract}
Variation in grain size is often observed in heavy sections of superalloy forgings because regions of the workpiece may undergo different deformation histories during upset-type forging operations; however, uniform, fine grain size is critical to achieving the desired balance of mechanical properties in forged products. Discussed in this paper is the effect of thermomechanical processing (TMP) approaches on the microstructure and key mechanical properties of Inconel ${ }^{\circledR}$ alloy 706 (IN-706). IN-706 is a precipitation strengthened nickel-iron based superalloy utilized in gas turbines, particularly large turbine components in land-based power generation engines.
\end{abstract}

To investigate TMP, forging preforms were machined from as-received ingot, billetized to refine the coarse ingot grain structure and then finished forged to the desired size prior to solution heat treatment aging. Resulting pancakes were solution heat treated $(\mathrm{SHT})$ at $1790-1810^{\circ} \mathrm{F}\left(977-988^{\circ} \mathrm{C}\right)$ for various times at temperature and cooled to room temperature at two cooling rates. Two-step aging of the pancakes was conducted at $1350^{\circ} \mathrm{F}\left(732^{\circ} \mathrm{C}\right)$ and $1150^{\circ} \mathrm{F}\left(621^{\circ} \mathrm{C}\right)$. Grain size and mechanical properties, including Charpy V-Notch (CVN), of solution treated and aged (STA) pancakes were evaluated and rationalized on the basis of TMP history. Microstructure in the as-finish forged pancakes exhibited an duplex grain morphology, with grain size in the range of ASTM 6.1 to 9.4. SHT was observed to eliminate the duplex grain structure and provide a more uniform final grain size of ASTM 3.3 to 5.1, depending upon the SHT time and temperature.

The duplex as-forged microstructure could be leveled after relatively short exposures at SHT temperatures. Sluggish grain coarsening characteristics were observed, thus longer SHT times at temperature did not unduly coarsen grain size. The duplex asforged microstructure was observed to be a function of microstructural and compositional inhomogenieties in the forgings. UTS, YS, Elongation and RA properties remained constant. However, CVN values were observed to vary with time-at-temperature in SHT. This CVN behavior for IN-706 is then rationalized on the basis of microstructural observations.

\footnotetext{
Superalloys $718,625,706$ and Various Derivatives Edited by E.A. Loria

The Minerals, Metals \& Materials Society, 1997
} 
Background

Gas turbines for the power generation market have become a major consumer of large Inconel ${ }^{\circledR} 706$ (IN-706) forgings for turbine components. 1 This critical application for forged IN-706 is particularly demanding in that the forgings needed are very large, to $90 \mathrm{in} .(35 \mathrm{~cm})$ in diameter, weights to $18,000 \mathrm{lbs}$. (8000 kgs.) or more, and thickness to $16 \mathrm{in} .(6.3 \mathrm{~cm})$ thick, and are therefore challenging to produce on existing heavy press equipment. 3,4 In addition to the very large size of these forgings, critical service criteria translate to the need for consistent and controlled final component properties including first tier strength, ductility, and toughness, measured via Charpy V-Notch impact or CVN. 1

Further, successful exploitation of IN-706 forgings focuses on important second tier properties that include fatigue crack growth rates, low and high cycle fatigue and elevated temperature properties such as creep and elevated temperature strength. In addition to performance-related mechanical properties, ultrasonic transmission (U.T.) characteristics are also extremely important to assuring satisfactory performance of these critical rotating parts. 1,6 Many of the above described important performancerelated mechanical properties as well as U.T. transmission characteristics are directly correlated to the absolute grain size as well as the uniformity of grain size throughout the parts and their typically heavy sections. Thus, the challenge to successful fabrication of these very large IN-706 forgings is development and capture of forging and thermomechanical processing (TMP) that achieves the desired combinations of microstructure, grain size, and resulting properties, including U.T. transmission. 1,3,6 The effects of TMP for heavy section IN-706 on microstructure-processing-properties relationships are discussed below.

In current applications for large IN-706 forgings, critical properties are developed by exploiting a two-step solution heat treatment (SHT) and age thermal treatment (STA) $2,6,8,10$ The STA heat treatment is executed after appropriate, frequently multiple-step forging working processes that refine the forged product microstructure from a relatively coarse starting ingot structure and achieve the desired forging shape in a cost and time efficient manner. The thermomechanical processes typically consist of well-designed and controlled forging deformation steps, generally at temperatures above the $\gamma^{\prime} / \gamma^{\prime \prime}$ solvus, followed by solution treatment with an appropriate quench process/quench rate and finally a two-step age.2,6,8

The T-T-T diagram for Alloy 706 after Heck 5 is an important tool that metallurgists have extensively utilized to guide development of critical thermomechanical processing (TMP) for the alloy, including the subject very heavy section forgings. Further, TMP development for IN-706 has borrowed heavily from its predecessor IN718 for process design. $7,8,9$ of significant concern in the design and execution of TMP is achieving satisfactory structures and grain size, within the constraints imposed by the bounds of poor thermal conductivity, restricted heat transfer, and limitations on deformation processes and deformation history due the forging size typical of IN-706 parts utilized in power generation turbine components. 6,11 The purpose of the within reported investigations in thermomechanical processing of $1 \mathrm{~N}-706$ was to provide 
increased knowledge and guidance for a robust TMP process for this alloy in large structural forged shapes through control of key structure-process-property interrelationships.

\section{Procedure}

A segment of 34 in. $(86 \mathrm{~cm}) \mathbb{I N}-706$ ingot, with following actual composition (weight percent), was obtained. The ingot was prepared into cylinders suitable for forging

$$
\text { Al }-0.26 \% \quad \mathrm{Cb}-2.95 \% \quad \mathrm{Cr}-16.03 \% \mathrm{Ni}-41.65 \% \quad \mathrm{Ti}-1.68 \% \quad \mathrm{Fe}-\mathrm{Bal} .
$$

into pancake forgings, with nominal dimensions of 8 in. $(200 \mathrm{~mm})$ dia. $\times 2.5$ in. $(63$ $\mathrm{mm}$ ) thick. The pancake forgings were produced using a multiple upset forging process, with a falling metal temperature scheme that parallels full size turbine wheel and spacer forging fabrication and working histories. Levels of forging strain, heat-up rates and cool-down rates were controlled to be comparable to those employed on production scale forgings and more specifically to reflect the bore mid-thickness location in full size forgings. One forging was kept in the as-forged condition to evaluation microstructure, grain size and mechanical properties.

Subsequent to forging, the thermal treatments applied included solution treatment $(\mathrm{SHT})$ at temperatures of 1790 and $1810^{\circ} \mathrm{F}\left(977\right.$ and $\left.988^{\circ} \mathrm{C}\right)$ for times at temperature of 1, 2, 4, and $8 \mathrm{hrs}$. for the lower SHT temperature and $3 \mathrm{hrs}$. at temperature for the higher SHT temperature. Post-SHT cooling rates for the pancake forgings were either 8 to $10^{\circ} \mathrm{F} / \mathrm{min}$. $\left(4.4\right.$ to $5.5^{\circ} \mathrm{C} / \mathrm{min}$.) or 25 to $30^{\circ} \mathrm{F} / \mathrm{min}$. $\left(13.9\right.$ to $16.7^{\circ} \mathrm{C} / \mathrm{min}$.). The twostep aging process employed was constant, e.g. $1350^{\circ} \mathrm{F}\left(732^{\circ} \mathrm{C}\right) 8 \mathrm{hrs}$., furnace cool at $100^{\circ} \mathrm{F} / \mathrm{hr}$. to $1150^{\circ} \mathrm{F}\left(621^{\circ} \mathrm{C}\right)$, hold for $8 \mathrm{hrs}$., air cool.

Solution treated and aged pancakes were then evaluated for the following mechanical properties and microstructural charateristics:

Room Temperature Yield and Ultimate Strength (Duplicate)

Room Temperature Elongation and Reduction in Area (Duplicate)

Room Temperature Charpy V-Notch (Duplicate)

ASTM Grain Size (Intercept Method)

General Microstructure both Light and SEM

\section{Results and Discussion}

Table 1 provides a surmmary of the tensile and charpy (CVN) test results for each TMP condition investigated. Results presented are the average of the two specimens tested. From these data and the plots of Yield and Ultimate Strength vs. SHT Time, Figure 1, and Elongation and Reduction in Area vs. SHT Time, Figure 2, it is apparent that the strength and ductility properties if $1 \mathrm{~N}-706$ in these studies are nearly independent of SHT temperature, SHT time and post-SHT cooling rate. For example, the Pancake No. 52, which was evaluated in the as-forged plus aged condition has strength and ductility that are on a par with pancakes that were subsequently solution treated, cooled and two-step aged. 
Table 1: Tensile and Charpy V Notch Properties of IN-706 Pancakes

\begin{tabular}{|c|c|c|c|c|c|c|c|}
\hline $\begin{array}{l}\text { Pancake } \\
\text { Number }\end{array}$ & $\begin{array}{c}\text { SHT Temp }\left({ }^{\circ} \mathrm{F}\right) / \\
\text { Time (hrs) }\end{array}$ & $\begin{array}{c}\text { Cooling } \\
\left.\text { Rate ( }{ }^{\circ} \mathrm{F} / \mathrm{Min}\right) \\
\end{array}$ & $\begin{array}{l}\text { YS } \\
\text { (Ksi) } \\
\end{array}$ & $\begin{array}{l}\text { UTS } \\
\text { (Ksi) }\end{array}$ & $\begin{array}{l}\mathrm{EL} \\
(\%) \\
\end{array}$ & $\begin{array}{l}\text { RA } \\
(\%) \\
\end{array}$ & $\begin{array}{c}\text { CVN } \\
\text { (ft-lbs.) }\end{array}$ \\
\hline 52 & None & N/A & 149 & 189 & 22 & 42 & 36 \\
\hline 51 & $1790 / 1$ & $8-10$ & 156 & 189 & 21 & 41 & 47 \\
\hline 44 & $1790 / 2$ & $8-10$ & 147 & 186 & 20 & 39 & 49 \\
\hline 42 & $1790 / 4$ & $25-30$ & 150 & 181 & 24 & 43 & 62 \\
\hline 48 & $1790 / 4$ & $8-10$ & 147 & 186 & 23 & 40 & 49 \\
\hline 41 & $1790 / 8$ & $8-10$ & 144 & 185 & 22 & 41 & 59 \\
\hline 46 & $1810 / 3$ & $8-10$ & 144 & 186 & 22 & 40 & 54 \\
\hline
\end{tabular}

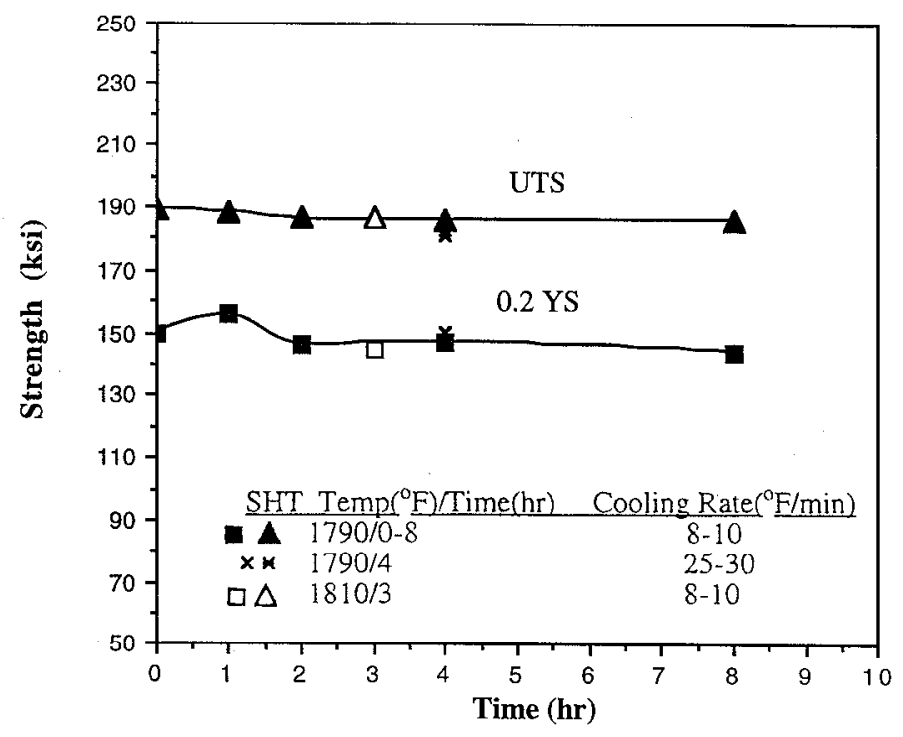

Figure 1 - R.T. Strength vs. SHT Time @ Temperature, IN-706 Pancakes

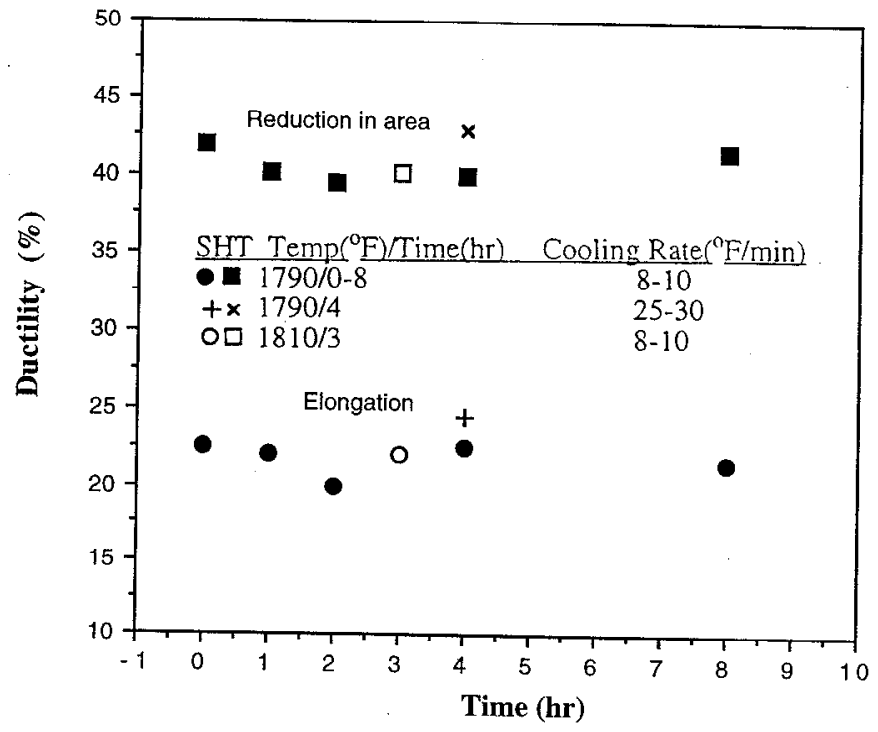

Figure 2 - R.T. Ductility vs. SHT Time @ Temperature, IN-706 Pancakes 
While within experimental error it appears that IN-706 tensile strength and ductility are not significantly affected by the TMP variations explored, from Table 1 and Figure 3 below it is clear that CVN properties are significantly affected by SHT temperature, SHT time@ @emperature and post-SHT cooling rate variables. In comparison to a "baseline" SHT @ $1790^{\circ} \mathrm{F}\left(977^{\circ} \mathrm{C}\right)$ and cooling rate of $8-10^{\circ} \mathrm{F} / \mathrm{min} .\left(4.4-5.5^{\circ} \mathrm{C} / \mathrm{min}\right.$.) for a comparable time@ temperature of 3 - 4 hrs., both a higher SHT temperature and a faster post-SHT cooling rate appear to improve CVN properties. Further, it is evident that as time @ the $1790^{\circ} \mathrm{F}\left(977^{\circ} \mathrm{C}\right)$ SHT temperature is increased, CVN first increases significantly, levels and then increases again at longer hold times. This observed CVN behavior then may influence production component TMP selection and

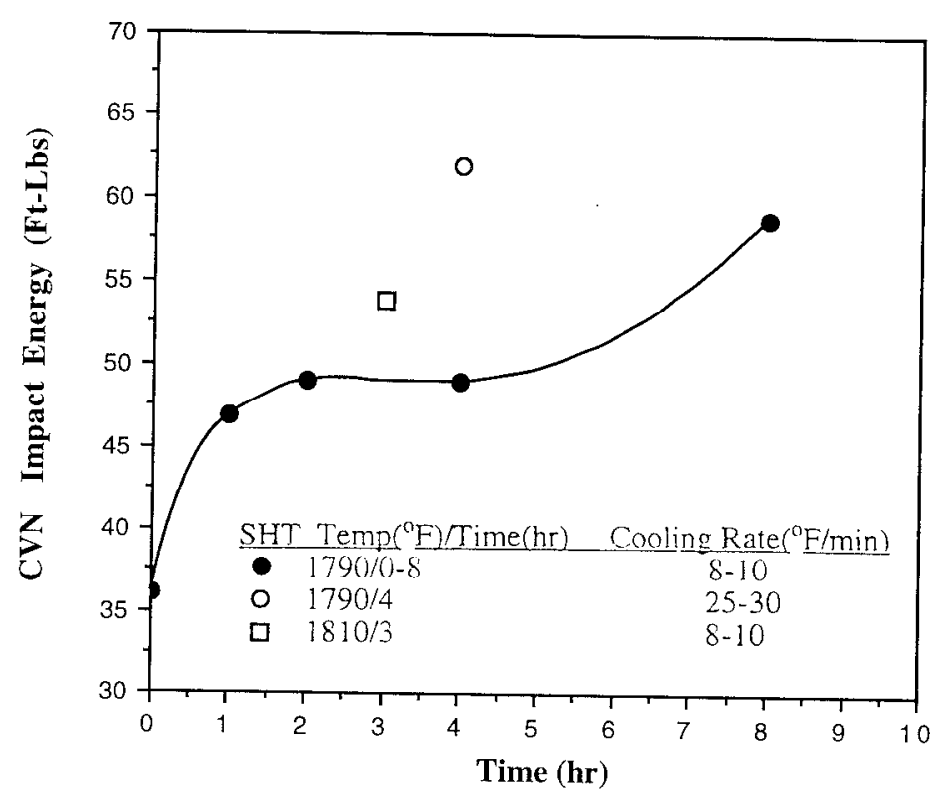

Figure 3 - R.T. CVN vs. SHT Time @ Temperature, IN-706 Pancakes

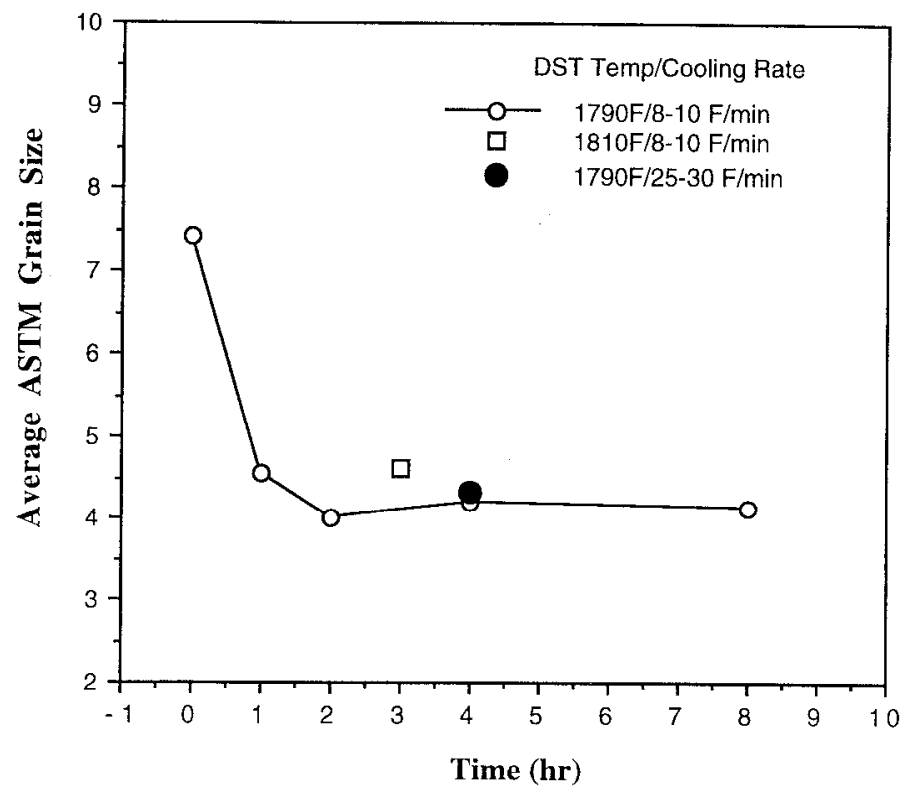

Figure 4 - ASTM Grain Size vs. SHT Time @ Temperature, IN-706 Pancakes 
thus merits further exploration and rationalization in terms of microstructural observations. The inflection point in the CVN vs. time at temperature in SHT observed in Figure 3 may have important implications in terms of design of TMP for full scale forgings. An understanding of the process-structure relationships which lead to the observed toughness behavior is therefore useful.

Table 2 - ASTM Grain Size of IN-706 Pancakes

$\begin{array}{ccccc}\begin{array}{c}\text { Pancake } \\ \text { Number }\end{array} & \begin{array}{c}\text { SHT Temp }\left({ }^{\circ} \mathrm{F}\right) / \\ \text { Time (hrs) }\end{array} & \begin{array}{c}\text { Cooling } \\ \text { Rate }\left({ }^{\circ} \text { F/Min) }\right.\end{array} & \begin{array}{c}\text { Grain Size } \\ \text { Ctr, Mid-Thk. }\end{array} & \begin{array}{c}\text { Grain Size } \\ \text { Edge, Mid-Thk. }\end{array} \\ 52 & \text { None } & \text { N/A } & 6.1-9.4 & 6.8-7.4 \\ 51 & 1790 / 1 & 8-10 & 3.9-5.0 & 3.7-5.0 \\ 44 & 1790 / 2 & 8-10 & 3.8-4.7 & 4.2-5.0 \\ 42 & 1790 / 4 & 25-30 & 3.6-4.9 & 3.6-5.0 \\ 48 & 1790 / 4 & 8-10 & 3.7-4.9 & 4.0-5.0 \\ 41 & 1790 / 8 & 8-10 & 3.3-4.7 & 4.0-4.9 \\ 46 & 1810 / 3 & 8-10 & 3.5-5.1 & 3.8-5.0\end{array}$

The first macrostructural/microstructural feature which may be explored to explain the observed CVN behavior is ASTM grain size. ASTM intercept grain size observations vs. TMP process conditions are outlined in Table 2 and graphically presented in Figure 4. Evident from these data is that the grain size in the as-forged structure may be duplexed, see Figure 5 below, with very fine and coarser grains coexisting and having resulted from the temperature-strain-strain rate history imparted in forging. Figure 5 illustrates the structure of Pancake 52, as-forged, in Table 2. Subsequent SHT tends to coarsen the grain size rapidly. Figure 6 illustrates the grain size for Pancake 44 Table 2, with 1 hour @ $1790^{\circ} \mathrm{F}\left(977^{\circ} \mathrm{C}\right)$. However, rate of grain coarsening levels for increasing SHT hold times @ $1790^{\circ} \mathrm{F}\left(977^{\circ} \mathrm{C}\right)$, up to 8 hours. Increasing the $\mathrm{SHT}$ to $1810^{\circ} \mathrm{F}\left(988^{\circ} \mathrm{C}\right)$ temperature slightly coarsens the grain size. Post-SHT cooling rate does not appear to have a major effect on grain size.

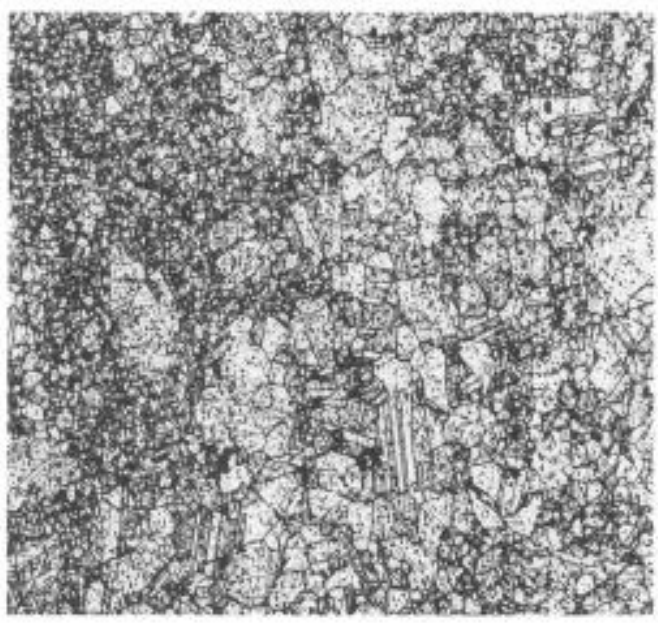

Figure 5 - Microstructure IN 706 Pancake 52 Magnification 200X, Etch: Kalling's

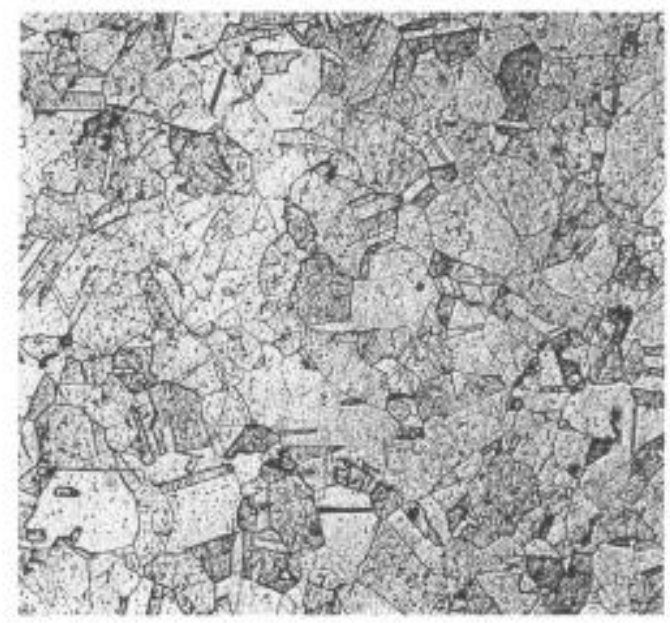

Figure 6 - Microstructure IN706 Pancake 44 Magnification 200X, Etch: Kalling's 
In order to rationalize the process-property relationships found, Tables 1 and 2, and in particular the CVN vs. time at temperature behavior, higher order microscopy was necessary. The identification of phases observed and discussed below was determined by extraction techniques. Figures 7 and 8 present SEM micrographs of Pancake No. 52, as-forged plus aged and Pancake No. 48, solution treated at $1790^{\circ} \mathrm{F}$ $\left(977^{\circ} \mathrm{C}\right)$ for 4 hours at temperature and aged.

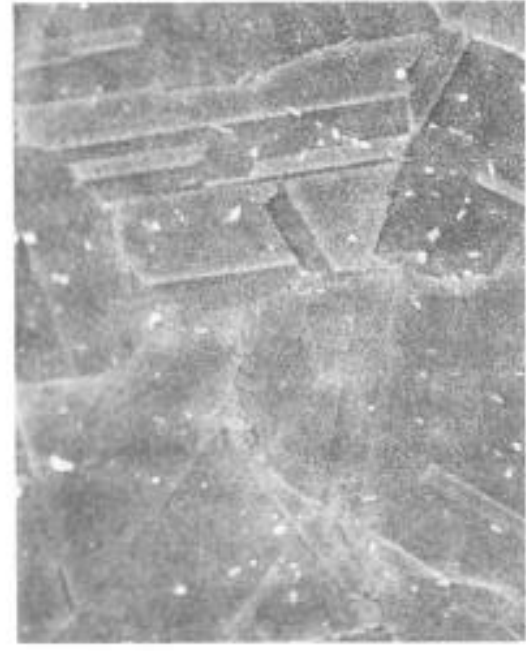

10um

Figure 7 - SEM Micrograph Pancake 52 Mag. 1000X, Etch Kalling's

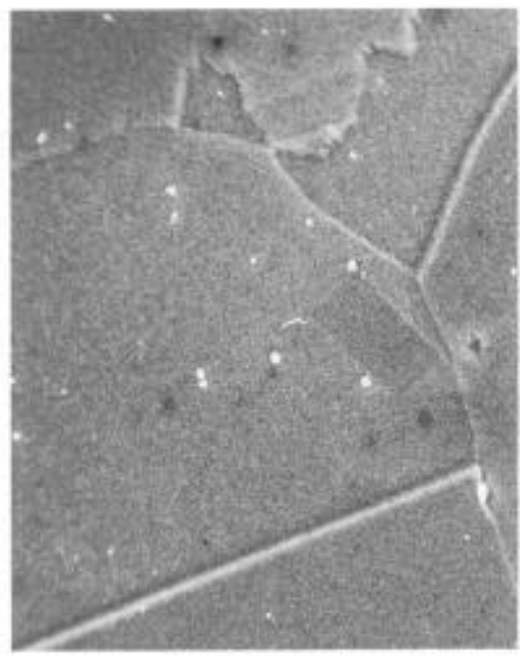

10um

Figure 8 - SEM Micrograph Pancake 48 Mag. 1000X, Etch Kalling's

The fine grains in the duplex structure of Pancake 52, Figure 5 and from Figure 7 are found to be contained in a region of high density of precipitates, e.g. (Nb,Ti)(C,N) and Laves phase ( $\mathrm{Fe}_{2} \mathrm{Nb}$-type) at grain boundaries, grain triple points and/or grain interiors. Compare with the coarser grain size and lower precipitation population of Pancake 48, Figure 8 . From Table 1, the grain size of Pancake 48 is essentially the same as that pictured in Figure 6, for Pancake 44. Furthermore, a higher concentration of $\mathrm{Nb}$ and $\mathrm{Ti}$ was also detected in the fine grain regions than in the coarser grain regions of the same part, e.g. Pancake No. 52. This concentration difference, likely to have had its root cause in a minor level of microsegregation in the starting ingot, may result in the observed higher density of $\delta$ and $\eta$ phases in the fine grain regions as well as a higher solvus temperature for both of these phases in the fine grained regions.

Formation of the duplex grain size microstructure may thus be related to the deformation conditions employed in forging and the phases present both during and after the multiple-step forging process. Fine carbides and/or carbonitrides may assist in development of fine grain structure by providing preferred nucleation sites for recrystallized grains. Such precipitates can also stabilize the grain size for longer hold times at temperature in SHT. Laves phase, observed in both the duplexed structure of the as-forged Pancake No. 52 as well as the coarser grained STA Pancake No. 44 , might be expected to form in the $\mathrm{Nb}$ rich matrix as $\delta$ phase 
dissolves. The formation of Laves can also provide stabilization of fine grain sizes with longer SHT times.

Post-SHT grain size is observed to initially coarsen slightly and then remain stable as SHT soak time lengthens largely on the basis of underlying precipitate stability or dissolution behavior in SHT. From microstructural observations, fine grain sizes are associated with higher precipitate concentrations, that in turn may be influenced by $\mathrm{Ti}$ and $\mathrm{Nb}$ concentration gradients, deformation history and SHT soak time. It is also observed that $\mathrm{CVN}$ properties of $\mathrm{IN}-706$ are related to grain size, e.g. finer or duplexed grains result in lower CVN values than coarser grain sizes. This investigation and other work 6 have shown that $C V N$ properties of $1 N-706$ are also influenced by grain boundary precipitation morphology and type. These grain size and grain boundary precipitate effects, as confirmed by microstructural observations, explain, in Figure 3 , the higher CVN value obtained with the slightly higher SHT temperature of $1810^{\circ} \mathrm{F}\left(988^{\circ} \mathrm{C}\right)$ for 4 hrs. @ temperature vs. $1790^{\circ} \mathrm{F}\left(977^{\circ} \mathrm{C}\right)$ for $4 \mathrm{hrs}$. $@$ temperature and the higher CVN value obtained for SHT @ $1790^{\circ} \mathrm{F}\left(977^{\circ} \mathrm{C}\right)$ with post-SHT cooling rate of $25-30^{\circ} \mathrm{F} / \mathrm{min}$. vs. $8-10^{\circ} \mathrm{F} / \mathrm{min}$. Finally, the dissolution characteristics of precipitate phases observed is likely to be influenced by minor compositional variations which may affect the propensity to form certain precipitates $(\delta, \eta$, Laves) and locally modify the solvi of these precipitates influencing their dissolution behavior at selected SHT temperatures.

Thus, it then follows that the "inflection point" in the IN-706 CVN vs. SHT Time @ Temperature curve (Figure 3 ) may be rationalized on the basis of precipitate and grain size behavior resulting from SHT temperature and SHT times @ temperature. While higher SHT temperatures and/or longer SHT times improve CVN, this achievement appears to be at the expense of average grain size. Other important forging characteristics may therefore be adversely influenced by higher SHT temperatures and/or lengthened SHT times at temperature to improve CVN including ultrasonic transmission capabilities where increased U.T. noise has been observed with increasing grain size. 1,6,11

\section{Conclusions}

1. For the $\mathrm{IN}-706$ forgings of this study, yield and ultimate strength, elongation and reduction in area mechanical properties were independent the range of solution treatment temperatures, from 1790 to $1810^{\circ} \mathrm{F}\left(977\right.$ to $\left.988^{\circ} \mathrm{C}\right)$ and cooling rates from $8-10^{\circ} \mathrm{F} / \mathrm{min}$. $\left(4.4\right.$ to $5.5^{\circ} \mathrm{C} / \mathrm{min}$ ) to $25-30^{\circ} \mathrm{F} / \mathrm{min}$. $\left(13.9-16.7^{\circ} \mathrm{C} / \mathrm{min}\right.$.) utilized.

2. The as-forged grain size of IN-706 forgings was duplexed. Grain size increased with increasing solution heat treatment temperature and with increasing time at temperature up to 2 hours @ $1790^{\circ} \mathrm{F}\left(977^{\circ} \mathrm{C}\right)$. Subsequently grain size did not increase significantly with hold times up to 8 hours @ $1790^{\circ} \mathrm{F}\left(977^{\circ} \mathrm{C}\right)$. Forgings with finer or duplexed grain sizes had lower CVN properties than forgings with coarser and/or more uniform grain sizes from being held @ SHT temperatures for longer times.

3. Charpy $V$ Notch properties on IN-706 forgings increased with increasing hold times@1790 $\mathrm{F}\left(977^{\circ} \mathrm{C}\right)$. However, CVN properties of IN-706 vs. SHT hold times displayed an inflection point in the range of times@ temperature from 2 to 5 
hours. CVN properties increased with SHT hold times greater than 5 hours. Further, CVN properties were observed to be improved with higher SHT temperatures and/or with faster post-SHT cooling rates.

4. The observed CVN property behavior as a function of thermomechanical processing is explained by underlying changes in frequency and morphology of key precipitates, including $\delta, \eta$, Laves and Ti/Nb carbides or carbonitrides, as functions of SHT temperature, time at temperature and cooling rate. Larger amounts (volume fractions) of these precipitates, whether at grain boundaries or grain interiors resulted in lower CVN properties. The inflection observed in CVN properties is likely to be associated with sluggish dissolution of these precipitates as time@ @emperature in SHT@1790 $@\left(977^{\circ} \mathrm{C}\right)$ is increased. Improved CVN properties with SHT @ $1810^{\circ} \mathrm{F}\left(988^{\circ} \mathrm{C}\right)$ and with the faster post-SHT is explained by modifications in precipitates within grain boundaries and grain triple points.

5. The propensity to form $\delta, \eta$, Laves, and carbide/carbonitride precipitates is associated with variations in local chemistry, possibly due to microsegregation in the starting ingot. Higher $\mathrm{Nb}, \mathrm{Ti}$ concentrations from microsegregation favor carbide formation and also favor $\delta, \eta$ and Laves formation. Further, higher hardening element concentrations may also change the solvi of these precipitates, influencing their dissolution rate in SHT.

6. Thermomechanical processing (TMP) of large IN-706 turbine wheels and spacers may therefore be successfully adjusted to balance key final forging properties such as CVN, grain size and U.T. transmission performance. These adjustments in TMP, within reason, can, from this investigation, be made without adversely affecting first tier tensile and ductility properties. Further investigation of effects on other second tier properties including low cycle fatigue, creep, fracture toughness, elevated temperature strength, etc. as functions of the TMP's described herein is appropriate.

\section{References}

1. Schilke, P.W., Pepe, J.W., Schwant, R.C., "Alloy 706 Metallurgy and Turbine Wheel Applications," Superalloys 718, 625 and 706, E.A. Loria, Editor, TMSAIME, 1994 April, pp. 1 - 14.

2. Inconel ${ }^{\circledR}$ Alloy 706, INCO Alloy International, 1974.

3. Fesland, J.P., Petit, P, "Manufacture of Alloys 706 Forgings," ibid, pp. 229-238.

4. Honjo, T, et.al. "Manufacturing and Mechanical Properties of a large Size Alloy 706 Disk by ESR Process," ibid, pp. 239-248.

5. Heck, K.A., "The Time-Temperature-Transformation Behavior of Alloy 706," ibid, pp. 393-404.

6. Kuhlman, G.W., Chakrabarti, A.K., Beaumont, R.A., Seaton, E.D., Radavich, J.F., "Microstructure-Mechanical Properties Relationships in Inconel ${ }^{\circledR} 706$ Superalloy," ibid, pp. 441-450.

7. Mataya, M.C., Robinison, M.L., Chang, D. "Grain Refinement During Primary Breakdown of Alloy 718."

8. Raymond, E.L., Wells, D.A., "Effects of Aluminum Content and Heat Treatment on Gamma Prime Structure and Yield Strength of Inconel Nickel-Chromium Alloy 706," Superalloy Processing, Proceedings of $2^{\text {nd }}$ International Conference, MCIC Report, MCIC Battelle Columbus Laboratories, 1972 September, pp. N-1 to N-21. 


\section{References (cont'd)}

9. Remy, L., Laniesse, J., Aubert, H., "Precipitation Behavior and Creep Rupture of 706 Type Alloys," Materials Science and Engineering, 38, 1979, pp. 227-239.

10. Moll, J.H., Maniar, G.N., Muzyka, D.R., "Heat Treatment of 706 Alloy for Optimum $1200^{\circ} \mathrm{F}$ Stress-Rupture Properties," Metallurgical Transactions, Volume 2, August 1971, pp. 2153-2160.

11. Chakrabarti, A.K., Emptage, M.R., Kinnear, K.P., et.al., "Grain Refinement in IN706 Disc Forgings Using Statistical Experimental Design and Analysis," Proceedings, $7^{\text {th }}$ International Symposium on Superalloys, TMS, 1992, pp. 517526. 